Journal of Research in Interprofessional

Practice and

Education

Vol. 1.1

November, 2009

\title{
"Mainstreaming" Interprofessional Education within Hospital Settings: Findings from a Multiple Case Study
}

\author{
Elisa Hollenberg, BA, BFA, BSW, MSW; Scott Reeves, MSc, PhD; \\ Mary Agnes Beduz, RN, MN; Lianne Jeffs, RN, BScN, MSc, PhD (c); \\ Debbie Kwan, BSc (Phm), MSc; Jacques Lee, MD, MSc, FRCPC; \\ Mandy Lowe, MSc, BSc (OT); Jane Merkley, RN, MSc; \\ Lynne Sinclair, BSc (PT), MA (Ad Ed); Maria Tassone, MSc, BSc (PT); \\ Ivy Oandasan, MD, CCFP, MHSc
}

\begin{abstract}
Background: Interest in interprofessional education (IPE) to promote effective interprofessional collaboration (IPC) has gained momentum across healthcare, professional education, and government sectors. In general, the IPE literature tends to report single-site studies. This article presents a rare study that reports a largescale multi-site IPE initiative. It draws upon a newly developed notion of mainstreaming-introduced to the literature by Barr and Ross-that helps illuminate the implementation issues related to an IPE initiative.

Methods and Findings: A realistic evaluation framework was employed to explore the overarching impact of this large initiative (involving 6 IPE programs within 13 hospitals) on the teaching hospital network in which it was implemented. Qualitative methods were used to gather a total of 142 interviews with program leaders, facilitators, and learners. Findings provide insight into the mainstreaming of IPE in relation to educational, professional, and organizational outcomes. Educational outcomes detail how inter-organizational partnerships developed among hospitals with the sharing of ideas and resources for implementing IPE and IPC. Professional outcomes describe learners' experiences of increased awareness of the policy agenda and the meanings and value they attach to IPE and IPC. Organizational outcomes demonstrate that interprofessional champions with senior management support and protected time were core mainstreaming elements, and yet participants outlined a range of concerns and desires for the sustainability of this IPE initiative.

Conclusions: This article provided empirical insight into the perceptions, ideas, and experiences of IPE from a wide range of program developers, facilitators, and attendees. Barr and Ross' concept of mainstreaming and the use of a realistic evaluation framework provide a useful way to illuminate the processes and outcomes of implementing a large multi-institutional IPE initiative.

Keywords: Interprofessional education; Interprofessional collaboration; Main-

streaming; Realistic evaluation
\end{abstract}

in Interprofessional

Practice and Education (JRIPE)

Vol. 1.1

(C) 2009

Corresponding author:

Elisa Hollenberg

Email:

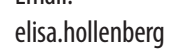

!@utoronto.cal

\section{Introduction}

In Canada, interprofessional collaboration (IPC) has become a mainstay for helping to address the health human resource shortage crisis [1]. IPC is defined as the provision of comprehensive health services to patients by multiple healthcare providers who work collaboratively to deliver the best quality of care in every healthcare setting [2]. IPE, defined as an activity "when two or more professions learn with, from 
11

Mainstreaming IPE in Hospital Settings

Hollenberg, Reeves, Beduz, Jeffs, Kwan, Lee, Lowe, Merkley, Sinclair, Tassone, \& Oandasan
Journal of Research in Interprofessional Practice and Education

Vol. 1.1

November, 2009 and about each other to improve collaboration and the quality of care" [3] has been advocated as an essential factor toward IPC [4].

Policy makers regularly call for effective interprofessional collaboration (IPC) as a key mechanism for tackling poor service delivery, reducing errors, and contributing to service modernization $[1,5]$. Research suggests that gains in patient care can be realized when staff regularly interact to negotiate and agree upon their work $[6,7]$. However, efforts to implement interprofessional practice are often limited by a weak grasp of how to work together, poor leadership of teams, the effects of professional socialization, status differentials between practitioners, and the impact of organizational change [8].

Increasingly, IPE is recognized as a necessary component for life-long learning among healthcare professionals to strengthen IPC [4,9]. In the United Kingdom, for example, IPE is often advocated as a solution to enhance the collaborative efforts of health and social care staff [5]. Findings from systematic reviews have substantiated claims that post-licensure IPE can enhance collaborative knowledge and skills as well as contribute to improvements in the delivery of care $[10,11,12]$. In the UK, the integration of IPE into professional education and other domains (e.g., pre- and post-qualifying education, professional regulatory bodies) has become more common. As a result, Barr and Ross [13] argue that IPE is becoming more of a mainstream activity. Important factors that have brought additional credibility and sustainability to IPE are securing government support and a commitment to IPE from professional associations, service agencies, universities, and regulatory bodies in the UK. Table 1 outlines elements that are essential to mainstreaming IPE [13].

Table 1

\section{Factors contributing to mainstreaming IPE}

Central government and policy-level support for incorporating IPE into professional pre-qualifying and post-qualifying education programs;

IPE training during pre-qualifying professional education within academic institutions and/or through academic internship placements in the practice setting developed in partnership with local health service agencies;

Developing and delivering work-based post-qualifying professional education IPE programs to staff in healthcare service agencies to develop a practice context that can consolidate pre-qualifying IPC training;

Having various institutions, including central government, professional associations, service agencies, universities, and regulatory bodies, mandate IPE as a requirement through their professional regulations;

Having systematic reviews to assemble an evidence base to prove the efficacy of IPE;

Examining and critically reviewing theoretical perspectives that are being developed by various disciplines to explain and teach IPE in academic settings.

Note: This table is a summary of Barr and Ross' factors [13] contributing to mainstreaming.

The "mainstreaming" of IPE and factors influencing the increasing interest, implementation, and success in delivery of IPE at a national level have been discussed in relation to a UK context. However, there is limited literature on 
12

Mainstreaming IPE in Hospital Settings

Hollenberg, Reeves, Beduz, Jeffs, Kwan, Lee, Lowe, Merkley, Sinclair, Tassone, \& Oandasan
Journal of Research in Interprofessional Practice and Education

Vol. 1.1

November, 2009 whether IPE has become mainstream in other national contexts such as Canada, where there has been comparable research, government interest and policy support for IPE.

This article presents findings from a recent Canadian IPE initiative, which is argued to be an example of IPE mainstreaming. The initiative involved 6 IPE programs and over 1,000 participants. It was designed to enhance knowledge about and interest in IPC among hospital staff and leaders working in different institutions within the same teaching hospital network during the same nine-month timeframe. The initiative was also intended to prepare hospital staff to implement and role model IPC for health professions students. The article examines the professional, educational, and organizational outcomes that were produced and how they may be examples of mainstreaming. It also examines how implementation processes in the national and local context may contribute to the initiative's outcomes and to the mainstreaming of IPE [13].

\section{Methods}

A realistic evaluation framework $[14,15]$ was employed to help illuminate the contextual influences, mechanisms, and the overarching impact of the initiative on the hospital teaching network in which it was implemented. Realistic evaluation differs from other forms of evaluation as it not only examines the outcomes or the effects of an intervention, but also seeks to understand the context and mechanisms (e.g., interventions) that contribute to these effects. Steven, Dickinson, and Pearson [16] state that, according to this approach, context consists of the broader historical, cultural, economic, geographical, and structural factors that exist at the time of the initiative. The term mechanism can refer to an educational intervention [16], as it does in this article.

\section{Design and methodology}

A multiple case-study approach [17] using qualitative methods (interviews and documents) was used to evaluate the large-scale initiative. Six IPE programs were designed to catalyze knowledge and interest in practice-based IPC.

The qualitative interviews contributing to the realistic evaluation approach, aimed to explore the nature of the mechanism (e.g., the large-scale IPE initiative) in this project. Using semi-structured interviews, facilitators and leaders of the programs were asked to describe their experience with the way their program was planned or implemented. Learners were asked to describe their learning experience. All participants were also asked about changes in perceptions, attitudes, awareness, readiness, and knowledge/skills; changes in behaviors towards collaboration; about what would be necessary to sustain interprofessional activities within their own workplaces; and about barriers and facilitators to change. Through these questions, the mechanisms and context factors that may have influenced the creation of the program's outcomes and impact were examined.

Documents generated during the initiative, including IPE program descriptions and meeting minutes, were also gathered. These data were used for the purposes of describing the context and mechanisms at play within this project. 
JRIPE

13

Mainstreaming IPE in Hospital Settings

Hollenberg, Reeves, Beduz, Jeffs, Kwan, Lee, Lowe, Merkley, Sinclair, Tassone, \& Oandasan
Journal of Research in Interprofessional Practice and Education

Vol. 1.1

November, 2009
Journal of Research in Interprofessional Practice and Education

Ethics approval was received to conduct this work, and as such, participation in interviews and questionnaires was voluntary, confidential, and anonymous.

\section{Data collection}

Qualitative interviews were distributed across the six IPE programs within the initiative using a purposeful sampling method to recruit participants from a range of different professional groups and project roles (learner, facilitator, leader) across the programs. There were a total of 142 interviews across programs, including 52 interviews with project leads, 30 with facilitators, and 60 with program attendees at the beginning $(N=63)$ and after the IPE programs were implemented $(N=79)$ (see Table 2). A total of 105 individuals from different professions participated in the interTable 2

Qualitative interviews

\begin{tabular}{|r|c|c|c|}
\hline & $\begin{array}{c}\text { Pre- } \\
\text { Program }\end{array}$ & $\begin{array}{c}\text { Post- } \\
\text { Program }\end{array}$ & Total \\
\hline Learners & 17 & 43 & 60 \\
\hline Leads & 26 & 26 & 52 \\
\hline Total & 63 & 10 & 30 \\
\hline
\end{tabular}
views. Due to the complexity of the projects, and depending on who agreed to interviews, only 37 individuals were interviewed twice while 68 were interviewed once. When only post-program interviews were conducted, questions about background and context were included from the early interview schedules.

Of the 105 participants interviewed, the majority were staff from the health professions $(52 \%, N=55)$, with $26 \%$ of participants from nursing $(N=27)$ and $14 \%$ from medicine $(N=15)$ (the remaining 8 participants were consultants hired to assist with the development/implementation of programs). The professions most represented were physiotherapy $(11 \%, N=12)$, social work $(10 \%, N=11)$, and occupational therapy $(7 \%, N=7)$.

\section{Analysis}

Interview data were tape-recorded and transcribed verbatim. Researchers worked together initially to develop a common coding framework that could be used across programs. To do so, the findings from the six IPE programs were divided up among research team members, who were asked to code a small number of learner, facilitator, and project leader interviews from these programs. The interviews were each coded using an inductive thematic analysis approach. In inductive thematic analysis, the researcher identifies themes using an open-coding method, without reference to a pre-existing framework such as an interview guide or a specific theoretical perspective [18]. The researchers then met to compare the results of their initial open coding to identify common themes across the same type of interview (e.g., learner, facilitator, project leader) and across the six programs. Common issues across the six programs were generated, resulting in a common coding framework 
14

Mainstreaming IPE in Hospital Settings

Hollenberg, Reeves, Beduz, Jeffs, Kwan, Lee, Lowe, Merkley, Sinclair, Tassone, \& Oandasan
Journal of Research in Interprofessional Practice and Education

Vol. 1.1

November, 2009 that was agreed upon for learners, facilitators, and leaders. Interviews from each program were then analyzed using this framework.

\section{Findings}

As noted above, the use of a realistic evaluation approach helps to explore and examine the relationship between the context, mechanism, and outcomes. This section of the article presents findings in three main parts. Firstly, background information (context) is offered, revealing how the national and local context helped create willingness for the development of this initiative. Secondly, information on the initiative and its associated six programs (mechanism) is provided. Finally, key outputs (outcomes) linked to the implementation of the initiative are presented.

\section{Context}

The 2003 First Ministers' Accord on healthcare Renewal in Canada [1] identified the importance of changing the way healthcare professionals are educated so that their education and training prepare them to practice interprofessional care [19]. This national directive was implemented in the province of Ontario through HealthForceOntario's key document, Interprofessional Care: A Blueprint for Action in Ontario [2]. The Blueprint for Action outlined a number of steps needed by educators, healthcare providers, regulators, and policymakers to enable healthcare providers to practice in a more collaborative manner across Ontario. This document helped set the context for advancing the interprofessional agenda across the province. Significant funding for these types of initiatives was granted through provincial competitions. Policy directives were being drafted for legislative changes through a Ministry of Health-appointed Health Profession Regulatory Advisory Council, who was asked to recommend "mechanisms to facilitate and support interprofessional collaboration between health colleges" [20] to support the advancement of interprofessional care. Political will for developing and implementing IPE was therefore high both nationally and provincially [21].

The IPE initiative described in this article was awarded one of the funding opportunities from the Ministry of Health and Long Term Care (MOHLTC) under the Interprofessional Mentorship, Preceptorship, Leadership and Coaching (IMPLC) fund. The funding brought together participants for this project from the University of Toronto and the Toronto Academic Health Sciences Network (TAHSN), (made up of 13 hospitals). The overall purpose of the project was to create a foundation to advance the practice of IPC through the development and implementation of IPE.

\section{Mechanism}

This interprofessional initiative involved the development of six IPE programs focused on the four main programmatic themes related to interprofessional leadership, mentorship, preceptorship, and coaching that were required for the funding award (see Table 3). Each of these programs was led by different hospital leaders 
Mainstreaming IPE in Hospital Settings

Hollenberg, Reeves, Beduz, Jeffs, Kwan, Lee, Lowe, Merkley, Sinclair, Tassone, \& Oandasan
Journal of Research in Interprofessional Practice and Education

Vol. 1.1

November, 2009

\section{Details on the interprofessional education programs}

\begin{tabular}{|c|c|}
\hline IPE program & Details \\
\hline $\begin{array}{l}\text { Leadership } \\
\text { (Hospital 1) }\end{array}$ & $\begin{array}{l}\text { Interprofessional teams of leaders from } 13 \text { teaching hospitals attended three phases over a } \\
\text { four-month period. Phase } 1 \text { was a three-day workshop on IPC and IPE concepts and theory. } \\
\text { Project teams were invited to develop an action plan for an IPE or an IPC collaboration initia- } \\
\text { tive within their organization. Phase } 2 \text { was a half-day session on early progress and next steps. } \\
\text { Phase } 3 \text { was a one and one-half-day workshop for leaders to share outcomes of IPE/IPC pro- } \\
\text { gram implementation. }\end{array}$ \\
\hline $\begin{array}{l}\text { Mentorship } \\
\text { (Hospital 2) }\end{array}$ & $\begin{array}{l}\text { Health providers were paired with a member of a different professional group over a three- } \\
\text { month period. Mentors and mentees attended two initial workshops covering 1) conflict res- } \\
\text { olution, teamwork, communication, and 2) IPE and IPC principles, theory, and concepts. A } \\
\text { networking database was created specifically to facilitate scheduling, evaluation, and in-per- } \\
\text { son or virtual meetings for participants. }\end{array}$ \\
\hline $\begin{array}{l}\text { Preceptorship } \\
\text { (Hospital 3) }\end{array}$ & $\begin{array}{l}\text { A manual and teaching tools were developed for teaching hospital staff and faculty interested } \\
\text { in developing and delivering their own student IPE placement programs. The training materi- } \\
\text { als were piloted and adapted based on feedback. Final tools for the IPE student preceptorship } \\
\text { program were produced for distribution across the teaching hospital network, including pres- } \\
\text { entation materials, handouts, and facilitation tips. }\end{array}$ \\
\hline $\begin{array}{l}\text { Coaching } 1 \\
\text { (Hospital 4) }\end{array}$ & $\begin{array}{l}\text { Three types of IPE coaching programs were newly developed and delivered to raise awareness } \\
\text { about IPC at different levels within the institution, including } 1 \text { ) an interactive e-learning } \\
\text { resource for all staff on IPC and patient- and family-centred care (PFCC) core concepts, 2) a } \\
\text { workshop to coach the general and sub-specialty medicine (GSM) team to work from an IPC- } \\
\text { PFCC model, and 3) a workshop coaching organizational leaders in IPC-PFCC concepts, theory, } \\
\text { and planning. }\end{array}$ \\
\hline $\begin{array}{l}\text { Coaching } 2 \\
\text { (Hospital 5) }\end{array}$ & $\begin{array}{l}\text { A half-day IPE coaching workshop was newly developed and delivered to coach an interpro- } \\
\text { fessional Emergency Department (ED) team to assess and promote the health and safety of } \\
\text { older patients in their care. This workshop was delivered over time until all staff from the large } \\
\text { ED department had attended in smaller subsets of interprofessional groups. }\end{array}$ \\
\hline $\begin{array}{l}\text { Coaching } 3 \\
\text { (Hospital 6) }\end{array}$ & $\begin{array}{l}\text { Coaching programs were newly developed and implemented at three levels to seed aware- } \\
\text { ness about IPE/IPC across the organization. Programs included 1) further developing skills and } \\
\text { leadership capacity of a pre-existing IPC leadership/coaching team, 2) IPE workshops on inter- } \\
\text { professional health assessment and patient-centered care, and 3) IPE workshops on IPC for } \\
\text { the general internal medicine (GIM) program. }\end{array}$ \\
\hline
\end{tabular}

and project teams. Over 1,000 individuals from a wide range of professional backgrounds engaged in the initiative as project leaders, facilitators, and learners.

A steering committee was responsible for overseeing the project as a whole. The collaborative efforts at this level helped to ensure that each of the six individual IPE initiatives and their sub-projects were strategically incorporated within the overall vision for the transformation of interprofessional care across the network. In addi- 
16

Mainstreaming IPE in Hospital Settings

Hollenberg, Reeves, Beduz, Jeffs, Kwan, Lee, Lowe, Merkley, Sinclair, Tassone, \& Oandasan
Journal of Research in Interprofessional Practice and Education

Vol. 1.1

November, 2009 tion, appreciative inquiry, an organizational development approach, was used to help support program development and delivery [22].

Toward the end of the initiative, a two-day conference was held to discuss project outcomes and organizational planning. The work of all the programs was brought together so that the broader community could also reflect on their learning and consider ways to continue its further advancement.

\section{Outcomes}

This section of the article presents the four major outcomes from the initiative-educational, professional, organizational, and a desire for sustainability. Educational outcomes refer to learning by project leaders, individually and collectively across the teaching hospital network, about the design, implementation, and delivery of IPE programs. Professional outcomes refer to how the IPE programs influenced the awareness, attitudes, perceptions, and knowledge of individual practitioners. Organizational outcomes refer to aspects of the initiative that were thought to be helpful for embedding IPE within host organizations delivering an IPE program. A desire for the sustainability of IPE within the teaching hospital network was a final outcome of the initiative reported, with suggestions for what would be necessary to achieve this goal.

\section{Educational outcomes}

Generally, participants gained insight into the advantages of working collaboratively with their clinical colleagues from different professional groups when planning and delivering IPE:

We chose a group of six people from very different professions, very different backgrounds, very different parts of the organization; ... we have a lot of fun, but also a lot of really creative ideas. It's really exciting to be co-creating something together. (Nurse, Project Leader)

As a result of this collaboration, many project leaders mentioned that the initiative had provided them with an impetus to review current educational practices and organizational policies through an interprofessional lens. Leaders also learned of the advantages of collaborating with other organizations. Interactive processes encouraged practitioners to come together and share ideas and resources and to network in relation to IPE development in a manner that had never occurred. As a result, a number of interpersonal and interprofessional, links and partnerships were formed between a variety of different practitioners, managers, and educators.

We can really learn from one another ... we are getting calls from the different [hospital] sites, asking questions about, "how are you doing this and that," so there's a good collegial sort of support which is developing out of it as well. (Nurse, Project Leader)

Participants gained new insights into the advantages of sharing interprofessional education tools with each other (i.e., training manuals, facilitation aides, curricula, and teaching materials), which were developed and shared between project partners.

Leaders expressed their appreciation of sharing resources, learning, and developing new connections and relationships across professions and organizations as a 
17

Mainstreaming IPE in Hospital Settings

Hollenberg, Reeves, Beduz, Jeffs, Kwan, Lee, Lowe, Merkley, Sinclair, Tassone, \& Oandasan
Journal of Research in Interprofessional Practice and Education

Vol. 1.1

November, 2009 result of this project. A new cohesiveness in relation to IPE planning to prepare the teaching hospital to accommodate pre-entry to practice placements was developed from the project within and across the network of healthcare institutions. Indeed, many participants felt that this initiative helped to create a new collaborative culture across the network of participating hospitals.

\section{Professional outcomes}

As the focus of the evaluation was to examine the overarching goal of the initiative to embed interprofessional approaches, professional outcomes are reported across programs rather than for individual programs. When grouped together, it was found that the set of IPE programs had collectively influenced the awareness, attitudes, perceptions, and knowledge of individual practitioners in ways that had the potential to enhance interprofessional care. Learners and leaders generally reported learning about the roles and scopes of practice of their professional colleagues.

Having them [other healthcare professionals] there and listening to what they were saying and what they were-all the things that each individual did on a daily basis-just opened our eyes more, I guess. And, of course, I have more respect for colleagues and everything else. (Nurse, Learner)

Whereas learners gained such insights during IPE programs, facilitators and leaders generated these insights through working with colleagues from other professions in planning and delivering IPE programming. Many felt that their IPE participation helped strengthen their understanding of how to collaborate and work more effectively as a member of an interprofessional team:

[The value was in] being interprofessional: learning the language of other professions. Learning the perspective and then seeing the whole picture has really, really given me a strong competence in my ability to look at the total patient situation that I didn't have. (Nurse, Facilitator)

Learners, facilitators, and leaders alike also gained a new understanding of the meaning of IPC:

I think what it [the initiative] did is it brought a focus in terms of a way of-and obviously a well-thought-out way of-looking at teamwork and interprofessional teamwork, a common definition, common approaches, some of the conceptual models. (Social Worker, Learner)

There were also new understandings among learners in relation to the policy agenda for IPC and IPE. Participants, including learners, facilitators, and leaders, had not realized that the movement was quite so large, before.

Despite general enthusiasm for IPC among learners who participated in interviews, there were observations by leaders about more skeptical participants attending the IPE programs who were not yet converted. Such participants were quick to point out the absence of randomized controlled trials, the lack of patient care outcome data, or increased system efficiency findings. Leaders were concerned about their inability to provide the kind of feedback requested. Leaders responded by 
Mainstreaming IPE in Hospital Settings

Hollenberg, Reeves, Beduz, Jeffs, Kwan, Lee, Lowe, Merkley, Sinclair, Tassone, \& Oandasan
Journal of Research in Interprofessional Practice and Education

Vol. 1.1

November, 2009
Journal of Research in Interprofessional Practice and Education

arguing that "the lack of evidence from randomized controlled trials doesn't mean that there is evidence to the contrary" (Psychologist, Project Leader). Leaders grappled with articulating the return on investment in ways that were evident to all stakeholders.

\section{Organizational Outcomes}

This section presents organizational outcomes associated with this initiative in relation to the goal of embedding IPE at the post-licensure level. This relates specifically to factors that need to be in place at the organizational level to promote and support IPE.

Learners noted the importance of increased time allotted for discussions about interprofessional collaboration. The discussions facilitated by the initiative would not normally occur in their organizations' regular work environment because of time constraints and the absence of regular opportunities to meet with their colleagues from other professional groups. One learner stated their appreciation of this time to interact:

I hope there is more opportunity, I know there is discussion, but I hope there is opportunity for this to be repeated because I think it was valuable. I think we get so few opportunities to work together other than the day-to-day clinical stuff that it is very valuable because you can't figure things out like that when you are in the middle of getting through your day's work. (Physiotherapist, Learner)

Collectively, leaders considered that it was necessary to bring together different healthcare professionals and managers within their hospitals who were acting as interprofessional "champions." They believed it would be important for the interprofessional champions to be less isolated in their individual institutions and to coordinate their educational strategies. The initiative was seen as being instrumental in bringing leaders together to work across clinical programs:

So you have five leaders who have been working in isolation for years with some interaction. But a project like this forces people to step it up to the next level and work on integrating ... ideas and really sharing in a much more meaningful and practical level because it all generates into work. (Physician, Project Leader)

Leaders also emphasized the importance of having a common agenda for IPE across the participating hospitals, supported by the university affiliated with all of the hospitals. This kind of external support was considered monumental in providing the momentum to embed and sustain the early gains associated with this initiative at an organizational level:

"they [the executive team] have sort of, a greater context to put to this discussion and when it's not just your hospital but it's a collaborative of hospitals and the university talking about the same thing, it adds a lot of support to the argument.... project is part of a bigger project. I think that's the more meat on the bones." (Physiotherapist, Project Leader) 
Mainstreaming IPE in Hospital Settings

Hollenberg, Reeves, Beduz, Jeffs, Kwan, Lee, Lowe, Merkley, Sinclair, Tassone, \& Oandasan
Journal of Research in Interprofessional Practice and Education

Vol. 1.1

November, 2009
Journal of Research in Interprofessional Practice and Education

As a result of having external support, it was noted that institutions were initiating changes to promote enhanced IPE. These changes included identifying local interprofessional champions and developing educational materials to support future training programs.

Following the delivery of the six interprofessional programs, there was agreement that a new organizational culture was evolving in many of the participating organizations. Indicators that were cited for this shift included senior management support for developing IPE and IPC, an adoption of collaborative practice protocols and hospital policies, and a pooling of institutional resources to capitalize on interprofessional gains from the initiative.

\section{Sustainability}

In addition to the outcomes that emerged from this large-scale initiative, participants began to share their reflections on what would be necessary to sustain IPE initiatives. There were suggestions for what was felt necessary at the educational, professional, and organizational levels.

As described earlier, in the absence of an evidence base for IPC, leaders felt it was important to find creative ways to promote this new approach. They hoped that their efforts would gradually advance the IPC approach within their institutions by increasing professional- and individual-level support for IPC.

Adequate representation and endorsement from all professions was also noted as critical for sustainability and success. In particular, concern was expressed about the limited involvement of physicians. Participants felt that future experiences should aim to ensure a higher degree of participation from this group, especially if they were going to be a mainstream professional development activity. Indeed, physician buy-in was regarded as a key element for success in the sustainability of such initiatives:

It was very good in terms of how much representation there was from various groups, but definitely the physician side is important, and the two doctors that came, it was great to have them. But, you know, it was a very small percentage of the group, because certainly in any hospital setting, if you don't have the doctors on board, it is hard to move forward with some things. So that was, that would have been good to have more involvement from them. (Physiotherapist, Learner)

To reinforce and embed professional outcomes, participants of this initiative also emphasized a need for IPC to be mandated as a professional requirement within their organizations.

To sustain educational outcomes across the teaching hospital network, leaders expressed a need for increased communication and joint planning with universities for IPE programs. Concern was articulated about the potential separation that would develop if the hospitals and the universities were not aligned with the values of IPE.

The university can't be developing curriculum around IPE for their students and then dumping them into an organization ... we really 
20

Mainstreaming IPE in Hospital Settings

Hollenberg, Reeves, Beduz, Jeffs, Kwan, Lee, Lowe, Merkley, Sinclair, Tassone, \& Oandasan
Journal of Research in Interprofessional Practice and Education

Vol. 1.1

November, 2009 need to have one agenda. I think this is a really unique opportunity for the university and the hospitals to work together and sort of break down the silos between those two big organizations on creating one strategy that crosses both areas. (Nurse, Project Leader)

Finally, there were suggestions by learners, facilitators, and leaders for factors that could enhance the sustainability of the initiative at the organizational level. Despite reporting that their interprofessional experiences had provided them with knowledge and confidence for developing more collaborative approaches, a number of participants were unsure about the actual practicalities of initiating such a widespread change within their institutions:

The practicalities and the realities of it are that it will take a lot of work to bring it to fruition ... we're just a little group here, it's only five people. So I think ... there are 2,700 people in this organization; how do we have an impact? But I am very excited about our [IPE] program and what we're doing, and I see that the learning we get from the project will help us to understand how we can move forward in other parts of the organization. (Nurse, Learner)

Educational reminders and refresher sessions were thought necessary to sustain knowledge and momentum at the organizational level within the hospitals. It was also considered that there was a need to train a larger group of facilitators within each institution.

\section{Discussion}

This article aimed to develop an understanding of the implementation of a large initiative involving six IPE programs and staff from a network of 13 teaching hospitals working in collaboration with a single university. Barr and Ross' [13] notion of mainstreaming IPE was employed as a lens through which to view the array of issues related to the development and implementation of a large IPE initiative.

A realistic evaluation approach was used to explore how contextual factors helped shape mechanisms that, in turn, contributed to the generation of a range of outcomes across the hospital teaching network. As indicated above, there were a unique set of contextual circumstances at the time of the initiative. The political will of the provincial government along with the opportunity for interprofessional funding contributed to the momentum of this initiative. In addition to contextual factors, there were key process factors, or mechanisms within the project, that can be linked to the project outcomes. The main process or mechanism of the initiative involved an interconnected set of IPE programs developed by leaders and their newly formed IPE development teams within their respective institutions.

Collectively, the programs were intended to develop different kinds of IPE activities that could be piloted through their initial delivery with this project, shared across organizations during the project, and then shared across the local academic health sciences network following the project. As stated earlier, it was also hoped that the initial implementation of these programs would begin to teach and advance 
21

Mainstreaming IPE in Hospital Settings

Hollenberg, Reeves, Beduz, Jeffs, Kwan, Lee, Lowe, Merkley, Sinclair, Tassone, \& Oandasan

Journal of Research in Interprofessional Practice and Education

Vol. 1.1

November, 2009
IPC practice among staff in the participating hospitals-a location where new health professionals were also prepared for practice. Although the individual programs contributed to a range of educational- and professional-level outcomes, the overarching mechanism was that these simultaneously developed programs would provide learning opportunities that went beyond the individual learning in order to have a wider impact on the local community.

As a large interprofessional initiative, this project provides an example of how multiple stakeholders can take on different roles through different projects to implement a single change process to advance IPE and IPC in a complex yet organized fashion. The educational, professional, and organizational outcomes detailed in this article assist also in articulating that different outcomes can be attained for those involved in an interprofessional change process.

The two principal educational-level outcomes of the project were increased collective knowledge for the development and design of IPE programs across the teaching hospital network and improved integration of IPE into the post-qualifying practice setting. These outcomes are linked to the above mechanisms. There were numerous opportunities for project leaders to meet and work together to develop their IPE programs through sharing about the status, challenges, and successes of their respective projects.

The professional-level outcomes involved gains in knowledge about IPC concepts at an individual level. These gains were made evident through the voices of participants and leaders. These individuals expressed more awareness of the scopes of practice of other health professionals, a new awareness of broad political support for IPE and IPC, and changes in personal attitudes, including confidence in working collaboratively, interprofessionally, and inter-organizationally. There were equal barriers to the influence of the IPE initiative as a whole on interprofessional attitudes and perceptions among frontline workers as participants challenged the value of IPC due to the lack of quantitative research evidence for this approach.

Sustainability factors identified through the study affirm factors articulated by Barr and Ross [13] in their mainstreaming framework. Beyond the initiative itself, additional factors were thought necessary to embed interprofessional initiatives into professional education in an enduring way within this setting. First, participants identified a need for partnerships between universities and practice settings to develop the practice environment and a commonly held agenda for IPE to accommodate students moving from the pre-qualifying to the post-qualifying setting for internship placements. As noted by Barr and Ross, such collaboration is necessary "to formulate a coherent and unifying rationale for career-long continuing professional education that interweaves uniprofessional, multiprofessional and interprofessional strands in university and workplace" [13, p. 100].

Second, there were concerns expressed by leaders for an evidence base to prove the efficacy of IPC that they could use to convince the non-converted to increase peer support for IPE within their institutions. Similarly, there were suggestions in this study that for participation in IPC to become mainstream, as suggested for IPE by Barr and Ross [13], it would need to be "written into regulations for professional 
Mainstreaming IPE in Hospital Settings

Hollenberg, Reeves, Beduz, Jeffs, Kwan, Lee, Lowe, Merkley, Sinclair, Tassone, \& Oandasan
Journal of Research in Interprofessional Practice and Education

Vol. 1.1

November, 2009

\section{Journal of Research in Interprofessional Practice and Education}

education by professional institutions and regulatory bodies, services agencies and central government" (p. 100). These requirements could increase the participation of less-represented professions in IPE programming and also increase chances that learning would be transferred to practice if the approach was mandated rather than voluntary. Interestingly, Barr and Ross call for this evidence base and for written regulations for IPE, whereas, in our findings, there was a call for articulating the evidence base and the need for accountability structures for the practice of IPC. This distinction may be related to the Canadian context that articulates the distinct but interdependent nature of IPE and IPC.

\section{Recent Developments}

Locally, since the completion of this project, there has been an increase in the number of interprofessional leaders hired such that they are currently in place in 11 out of 13 hospitals. IPE placements have been piloted in 12 out of 13 hospitals. Many of the original participants and leaders meet regularly through a community of practice forum to continue to learn about how to advance interprofessional activities across local networks.

At the provincial level, three more funding cycles have been put into place for advancing interprofessional initiatives in the province of Ontario. Ontario is also in the process of implementing the Blueprint for Action through its HealthForceOntario strategy [2]. At the national level, IPE accreditation principles have recently been released for six health professional educational programs in Canada [23]. As a result of these developments, the interprofessional activities continue to evolve within Canada at a range of different (local, provincial, and national) levels and across educational and practice settings.

\section{Conclusion}

This article provided empirical insights into the perceptions, ideas, and experiences of IPE from a wide range of program developers, facilitators, and attendees who participated in a large multi-institutional IPE initiative. Barr and Ross' [13] concept of mainstreaming has provided a useful frame to help examine the processes of implementing a large-scale IPE initiative. The findings indicate that the mainstreaming of IPE is possible through bringing together hospitals in the same teaching hospital network to participate in a strategic process to learn about IPE and IPC.

\section{Acknowledgements}

We would like to thank all of the participants, who generously gave up their time to participate in this study, for their support. We would also like to acknowledge the Ontario Ministry of Health and Long-Term Care through the Interprofessional Mentorship, Preceptorship, Leadership and Coaching Fund for their funding support of the project and its evaluation.

\section{Competing interests}

The authors have no competing interests. 
Mainstreaming IPE in Hospital Settings

Hollenberg, Reeves, Beduz, Jeffs, Kwan, Lee, Lowe, Merkley, Sinclair, Tassone, \& Oandasan
Journal of Research in Interprofessional Practice and Education

Vol. 1.1

November, 2009

\section{References}

1. Health Canada (2006,_May)_2003 First Ministers' ascord_on healthsate renewzal _Health Canada, website; 'htttp://_wwww.hc_sc. gc. 'eng.phpi' [March 19, 2009].

2. Interprofessional Care Steering Committee. (2007). Interprofessional care: A blueprint for action

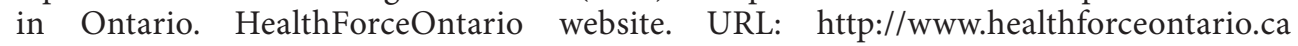

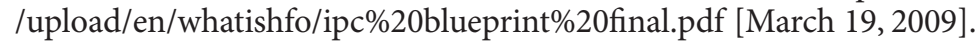

3. Centre for the Advancement_of_Interprofessional_Education. (2002). Defining IPE. CAIPE website. URL:'htttp://_www_caipe.org.ulk/about-us_/defining-ipes [March 19, 2009].

4. D'Amour, D., \& Oandasan, I. (2005). Interprofessionality as the field of interprofessional practice and interprofessional eduation: An emerging concept. Journal of Interprofessional Care, 19(S1), 8-20.

5. Department of Health. (2001). Working together, learning together: A framework for lifelong

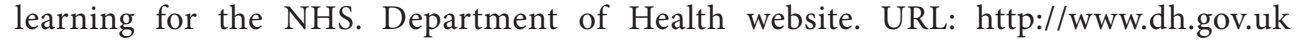

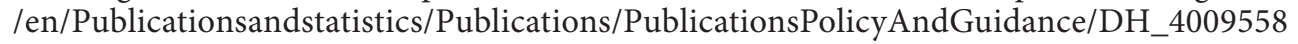
[March 19, 2009].

6. Schmitt, M.H. (2001). Collaboration improves the quality of care: Methodological challenges and evidence from US healthcare research. Journal of Interprofessional Care, 15(1), 47-66.

7. Zwarenstein, M., \& Reeves, S. (2006). Knowledge translation and interprofessional collaboration: Where the rubber of evidence based care hits the road of teamwork. Journal of Continuing Education for the Health Professions, 26(1), 46-54.

8. Simpson, A., Bowers, L., Alexander, J., Ridley, C., \& Warren, J. (2005). Occupational therapy and multidisciplinary working on acute psychiatric wards: The Tompkins acute ward study. British Journal of Occupational Therapy, 68(12), 545-552.

9. Oandasan, I., \& Reeves, S. (2005). Key elements for interprofessional education. Part 1: The learner, the educator and the learning context. Journal of Interprofessional Care, 19(S1), 21-38.

10. Barr, H., Koppel, I., Reeves, S., Hammick, M., \& Freeth, D.S. (2005). Effective interprofessional education: Assumption, argument and evidence. London: Blackwell Science.

11. Reeves, S., Zwarenstein, M., Goldman, J., Barr, H., Freeth, D.S., Hammick, M., \& Koppel, I. (2008). Interprofessional education: Effects on professional practice and healthcare outcomes. Cochrane Database of Systematic Reviews, Art. No.: CD002213. DOI: 10.1002/14651858.CD002213.pub2.

12. Barrett, J., Curran, V., Glynn, L., \& Godwin, M. (2007). CHSRF synthesis: Interprofessional collaboration qud_quality primary healthcare. Canadian Health Services Research Foundation website.

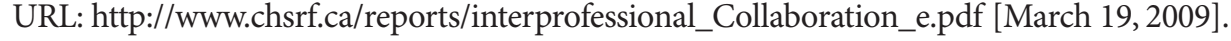

13. Barr, H., \& Ross, F. (2006). Mainstreaming interprofessional education in the United Kingdom: A position paper. Journal of Interprofessional Care, 20(2), 96-104.

14. Pawson, R., \& Tilley, N. (2007). Realistic evaluation. London: Sage Publications.

15. Reeves, S. (2008). Developing and delivering practice-based interprofessional education. Munich: VDM Publications.

16. Steven, A., Dickinson, C., \& Pearson, P. (2007). Practice-based interprofessional education: Looking into the black box. Journal of Interprofessional Care, 21, 251-264.

17. Yin, R.K. (1989). Case study research: Design and methods. Newbury Park, CA: Sage Publications.

18. Braun, V., \& Clarke, V. (2006). Using thematic analysis in psychology. Qualitative Research in Psychology, 3, 77-101.

19. Health Council of Canada. (2005). healthcare renewal in Canada:Acselerating shange.

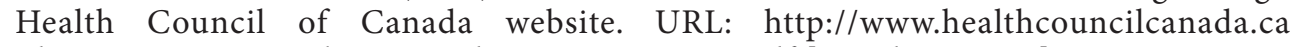
L_docs_/rpts_/2005/Accelerating_Change_HC_C_2005.pdf__[March 19, 2009].

20. Health Professions Regulatory Advisory Council (HPRAC). (2008). Consultation discussion guide on issues related to the ministerial_referral on_interproferssional collaboration among health colleges. HPRAC website. URL:'http:_/_wwww_hprac_org/en_'[March 19, 2009].

21. Federal/Provincial/Territorial Advisory Committee on Health Delivery and Human Resources. (March 2007). A framework for collaborative pan-Canadian health human resources plan=

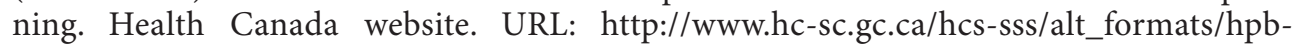
'dgps/pdf/pubs/hhhr/2007-frame-cadre/2007-frame-cadre-eng.pdf́t'[March 19, 2009].

22. Cooperrider, D., \& Srivastva, S. (1987). Appreciative inquiry in organizational life. In R. Woodman \& W. Pasmore (Eds.), Research in organizational change and development: Volume 1 (pp. 129169). Greenwich, CT: JAI Press.

23. Health Canada. (n.d.). Accreditation of Interprofessional Health Education (AIPHE): Principles and practices for integrating interprofessional education into_the_accreditation_standards_for,

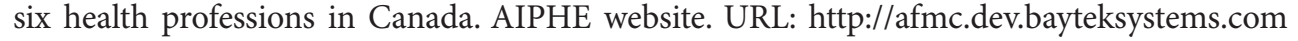

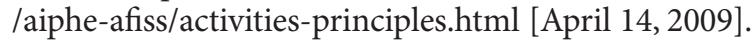

